Research Article

\title{
Wear Characteristics of Dense Fine Particles Solid-Liquid Two-Phase Fluid Centrifugal Pump with Open Impellers
}

\author{
Yanping Wang $\mathbb{D},{ }^{1}$ Chuanfeng Han, ${ }^{1}$ Ye Zhou $\mathbb{D}^{\circ},{ }^{2}$ Zhe Lin $\mathbb{D}^{\circ},{ }^{1}$ Jianfeng Ma, ${ }^{3}$ Xiaojun Li $\mathbb{D}^{1},{ }^{1}$ \\ and Wei Zhang \\ ${ }^{1}$ Faculty of Mechanical Engineering and Automation, Zhejiang Sci-Tech University, Hangzhou, Zhejiang 310018, China \\ ${ }^{2}$ China Institute of Water Resources and Hydropower Research, Beijing 100038, China \\ ${ }^{3}$ ZheJiang Fuchunjiang Hydropower Equipment Company Ltd., Hangzhou, Zhejiang 311501, China
}

Correspondence should be addressed to Zhe Lin; linzhe0122@zstu.edu.cn

Received 7 December 2020; Revised 11 January 2021; Accepted 29 March 2021; Published 7 April 2021

Academic Editor: Ling Zhou; lingzhou@ujs.edu.cn

Copyright $(2021$ Yanping Wang et al. This is an open access article distributed under the Creative Commons Attribution License, which permits unrestricted use, distribution, and reproduction in any medium, provided the original work is properly cited.

The demand for a centrifugal pump with open impellers for conveying dense fine particles in solid-liquid two-phase flow has increased significantly in actual engineering. The wear of dense fine particles on the centrifugal pump is also exceedingly prominent, which affects the engineering efficiency and economic benefits. The two-phase flow in the open centrifugal pump is three-dimensional and unsteady; the movement of high-volume concentration particles in the centrifugal pump and its mutual influence on the two-phase flow, which results in the calculation of wear, are very intricate. To study the wear characteristics of the centrifugal pump with open impeller with high-volume concentration particles more accurately, numerical simulation and experimental comparison are carried out for the impeller wear of dense fine particles transported by the centrifugal pump with open impellers. Considering the relationship between particles and walls, we used the Fluent 18.0 built-in rebound function and wear model. The RNG k- $\varepsilon$ model and the DDPM model were adopted in the numerical simulation, and the numerical solution for centrifugal pump wear was performed under flow rate $\left(9.6 \mathrm{~m}^{3} \cdot \mathrm{h}^{-1}, 12.8 \mathrm{~m}^{3} \cdot \mathrm{h}^{-1}, 16 \mathrm{~m}^{3} \cdot \mathrm{h}^{-1}\right.$, and $\left.19.2 \mathrm{~m}^{3} \cdot \mathrm{h}^{-1}\right)$, different particle sizes $(0.048 \mathrm{~mm}, 0.106 \mathrm{~mm}, 0.15 \mathrm{~mm}, 0.27 \mathrm{~mm}$, and $0.425 \mathrm{~mm})$, and different particle volume concentrations $(10 \%, 15 \%, 20 \%, 25 \%$, and $30 \%)$, respectively. By comparing the serious wear positions of the impeller, the experimental results correspond well with the numerical simulation, which can be used to predict and study the wear characteristics of the impeller. The results show that the most serious area of blade wear is the middle part of the pressure surface, followed by the middle part of the upper part of the blade. The wear of the impeller is greatly affected by relevant parameters, such as pump flow rate, particle diameter, and particle volume concentration. These results can provide some basis for the wear-resistant design of dense fine particle impeller.

\section{Introduction}

There are complex flow problems in multiphase fluid transportation [1-4]. The solid-liquid two-phase centrifugal pump is an important piece of equipment for the hydraulic transportation of solid particles. In the process of conveying particles, due to the collision between the particles and the components in the pump (such as impeller and volute), the components in the pump are worn out [5]. The presence of particles will destroy the original flow field and the protective layer of the wall, resulting in performance degradation and wear damage [6-10], which further leads to frequent replacement or maintenance, and the corresponding conveying system needs to be stopped, thus leading to the significant increase of the conveying costs. The research of Wilson et al. [11] showed that the shutdown cost of a large mine is about $1 \times 10^{5} \$ /$ hour. Therefore, the internal wear of centrifugal pumps is one of the important study directions of solid-liquid two-phase flow centrifugal pumps.

There are many influencing factors for the wall wear problem of solid-liquid two-phase flow. The scholars have done a lot of research on the characteristics of solid-liquid two-phase flow. Gandhi et al. [12] studied the influence of particle diameter changes on wear and obtained the correlation between the wear and particle size. Ben-Ami et al. 
[13] established a wear model by studying the impact angle of particles and the wear law of surface materials on the wall. The volume concentration and sharpness of particles are also important factors for wall wear. The study of Nan et al. [14] showed that the flow rate affects the speed of the particles and then affects the wear performance. Within a certain range, the sharpness of the particles has a greater impact on the wall wear performance. Regarding the effect of particle volume concentration on the wear of solid-liquid two-phase flow, the study of Lai et al. [15] showed that the change of volume concentration will affect the position of impeller wear. Zhang's simulation and analysis of two-phase flow showed that the abrasion on the pressure side of the impeller of a centrifugal pump is higher than other parts when conveying high-volume concentration particles [16]. Adamczyk et al. [17] used the combination of DDPM and Euler-Euler to calculate the flow of circulating particles in the fluidized bed and, compared with the experiment, obtained a particle motion model suitable for the fluidized bed. Ou et al. [18] used the DDPM and KTGF models to carry out the corresponding numerical simulations on the wear of the elbow pipe under high-volume concentration coal conveying. The results showed that for the movement of particles under the resistance of centrifugal force and secondary flow, when they pass the elbow, partial reunion occurs, and the larger particles are susceptible to impact the curved back, which has a more obvious impact on erosion and wear. Jain et al. [19] studied the influence of different particle properties on the flow characteristics of fluidized beds through radioactive particle tracking technology and DDPM, and the results showed that DDPM can effectively predict the average particle velocity.

To make better use of solid-liquid two-phase centrifugal pump wear simulation to predict its experimental results, the relationship between particles and the wall (including wall rebound function and wall wear function) should be considered. Many scholars have proposed wall rebound functions that are more in line with the experiment according to different research directions. Sommerfeld and Huber [20] obtained the parameters of the wall rebound model (such as the coefficient of restitution and friction coefficient) based on the experimental data. The modified wall rebound function can predict the experiment well. Forder et al. [21] proposed the corresponding wear models through experiments and proposed a corresponding particle rebound model in combination with particle angles and wall materials to better study the wear mechanism of control valves. Based on the wear data of flat specimens in water or airflow and $90^{\circ}$ standard elbows in airflow, E/CRC [5] obtained a new erosion equation and combined CFD with simulating and predicting the experiment. The wear rate and experimental results are in good consistency. Regarding the wear in the process of conveying solid particles in a fluidized bed, Bitter $[22,23]$ proposed a wall wear function based on the movement properties of the particles, the hardness of the material, and the elastic parameters and explained the wear phenomenon of the fluidized bed in the experiment. By studying the wear characteristics of the particle shape, velocity, shooting angle, and different material properties on the wall surface, Neilson and Gilchrist [24] proposed the corresponding wear function to explain the wear phenomenon in the experiment. By studying particle properties and wall material properties (hardness and load relaxation), Oka $[25,26]$ proposed wear functions for different materials. Huang [27] established a wear function including particle collision speed, angle, and particle size and wall material properties for the particle-wall wear characteristics during the jet process, which were in good agreement with the wear experiment of Finn [28]. Regarding the wear caused by the inhalation of solid particles by the turbine, G \& T [29] proposed related particle rebound model and wall wear models based on the hydrodynamic resistance of the solid particles, the particle's rebound on the wall, and the wall wear, which were used to predict the relevant parts of the turbine, wear location, etc. However, the calculation of the three-dimensional nonconstant value of wear of centrifugal pumps that transport high-volume concentration solidliquid two-phase flow is still very small. In this work, to predict the overall wear performance of the centrifugal pump with open impeller under the condition of the highvolume concentration of solid-liquid two-phase flow, the method of three-dimensional indeterminate constant value analysis and the DDPM model are used and the influence of relevant parameters (flow rate, particle diameter, and volume concentration) on the wear characteristics of centrifugal pump flow components is studied. The results of this study are helpful to develop high-volume concentration solid-liquid two-phase flow centrifugal pumps, such as applying hard material [30] to wear-prone areas, avoiding unnecessary downtime, and reducing operating costs.

\section{Mathematical Model}

To predict the wear performance of the centrifugal pump, the numerical calculation includes the following conditions: basic assumptions, the establishment of solid-liquid twophase flow control equation, the analysis of particle forces, and the selection of particle-wall collision function and wear function.

2.1. Basic Assumption. The solid-liquid two-phase flow inside the model pump is extremely complicated. To simplify the calculation and improve the accuracy of the numerical simulation results, the following assumptions are adopted:

(1) The continuous phase (water) is an incompressible fluid, and the physical properties of each phase are constant

(2) The particles are spherical glass beads with uniform particle size, regardless of the change in particle shape

(3) The influence of temperature on the two-phase flow field is not considered

(4) The collision between the particles and the wall is an elastic collision

(5) The liquid phase and the solid phase adopt two-way coupling, and so on 
2.2. Solid-Liquid Two-Phase Governing Equation. The twophase flow in the solid-liquid two-phase centrifugal pump is a turbulent flow. Considering the mixed movement and interaction of liquid and particles and the high-volume concentration of solid particles $(C \geq 10 \%)$, the EulerLagrange equation is used in this article to describe the liquid and solid phases in continuous media. Based on the principle of mass exchange and momentum conservation of incompressible two-phase flow, a basic solid-liquid two-phase governing equation, which is adopted by the Fluent 18.0 theory guide, is established:

$$
\frac{\partial}{\partial t}\left(\alpha_{i} p_{i}\right)+\nabla \cdot\left(\alpha_{i} p_{i} u_{i}\right)=\sum_{j=1}^{n}\left(\dot{m}_{j i}-\dot{m}_{i j}\right) .
$$

The momentum equation that is adopted by the Fluent 18.0 theory guide is as follows:

$$
\begin{aligned}
\frac{\partial}{\partial t}\left(\alpha_{i} \rho_{i} u_{i}\right)+\nabla \cdot\left(\alpha_{i} \rho_{i} u_{i} u_{i}\right)= & -\alpha_{i} \nabla p+\nabla \cdot\left[\alpha_{i} \mu_{i}\left(\nabla u_{i}+u_{i}^{T}\right)\right]+\alpha_{i} \rho_{i} g+\sum F \\
& +\left[\sum_{j=1}^{2} k_{j i}\left(u_{j}-u_{i}\right)+\dot{m}_{j i} u_{i j}-\dot{m}_{i j} u_{j i}\right]+K_{D S}\left(u_{s}+u_{j}\right)+S_{D E}, \\
\sum F= & F_{V}+F_{S}+F_{L},
\end{aligned}
$$

where $i=1,2$ indicates the liquid and solid phase; $\rho_{i}$ is the density of $i$ phase; $n$ is the number of phases; $p$ is the mixedphase pressure; $\alpha_{i}$ is the volume fraction of $i$ phase; $v_{i}$ is the relative velocity of $i$ phase; $\dot{m}_{\mathrm{ij}}\left(\dot{m}_{\mathrm{ji}}\right)$ indicates the mass transfer from $i$ phase to $j$ phase; $\mu_{i}$ is the viscosity of $i$ phase; $u_{\mathrm{ij}}\left(u_{j i}\right)$ represent the phase velocity of $i(j)$ phase and $j(i)$ phase, if $\dot{m}_{\mathrm{ij}}>0$ (the mass of the $i$ phase is transferred to the $j$ phase), then $u_{\mathrm{ij}}=u_{i}$ and if $\dot{m}_{\mathrm{ij}}<0$ (the mass of the $j$ phase is transferred to the $i$ phase), then $u_{\mathrm{ij}}=u_{j}$; (the same, if $\dot{m}_{\mathrm{ji}}>0$, then $u_{\mathrm{ji}}=u_{j}$; if $\dot{m}_{\mathrm{ji}}<0$, then $\left.u_{\mathrm{ji}}=u_{i}\right) ; S_{\mathrm{DE}}$ represents the explicit part of the momentum exchange phase (provided by DPM); $u_{s}$ represents the average velocity of discrete phase particles; $K_{\mathrm{DS}}$ represents the momentum exchange coefficient between the average phases of particles; $k_{\mathrm{ji}}=k_{\mathrm{ij}}$ the exchange coefficient between phases.

$F_{V}$ represents the virtual mass force, which accelerates the fluid surrounding the particles. When the particle density is greater than the fluid density, this force cannot be ignored. The corresponding equation is as follows:

$$
F_{V}=C_{\mathrm{vm}} \frac{\rho}{\rho_{p}}\left(u_{p} \nabla u-\frac{u_{p}}{\mathrm{~d} t}\right) .
$$

In the formula, when the particles are spherical, the virtual quality coefficient $C_{\mathrm{vm}}$ is 0.5 [31]; $u_{p}=\mathrm{d} x / \mathrm{d} t, u$ represents fluid velocity, $u_{p}$ represents particle velocity, and $\rho_{\mathrm{p}}$ represents particle density.

$F_{S}$ represents the Saffman force, which means that when the flow field has a large velocity gradient (such as near the wall), the velocity of the particle surface is different; that is, the pressure on the surface is different, which results in a difference between the particle and the fluid. For the force at the vertical velocity, the corresponding governing equation is as follows:

$$
F_{S}=1.62 d_{p}^{2} \sqrt{\mu \rho_{1}}\left(u-u_{p}\right) \sqrt{\left|\frac{\partial u}{\partial x}\right|} .
$$

Regarding the Saffman force under high Reynolds, the literature [32] proposed the following amendments:

$$
\begin{aligned}
C_{S} & = \begin{cases}\left(1-0.3314 \alpha^{0.5}\right) \exp \left(-\frac{\operatorname{Re}_{p}}{10}\right)+0.3114 \alpha^{0.5}, & \left(\operatorname{Re}_{p} \leq 40\right), \\
0.0524\left(\alpha \times \operatorname{Re}_{p}\right)^{0.5}, & \left(\operatorname{Re}_{p} \geq 40\right),\end{cases} \\
\alpha & =d_{p} \cdot \frac{|\partial u / \partial Y|}{\left|u-u_{p}\right|}, \\
\operatorname{Re}_{p} & =\frac{\rho d_{p}\left|u-u_{p}\right|}{\mu},
\end{aligned}
$$

where $R e_{p}$ is the particle instantaneous Reynolds number. 
$F_{L}$ represents the lift force of the particle in the liquid, and the lift force of the secondary phase $i$ in the main phase $j$ can be expressed as follows:

$$
F_{L}=-C_{l} \rho_{j} \alpha_{i}\left(u_{j}-u_{i}\right) \times\left(\nabla \times u_{j}\right) .
$$

In the above formula, $C_{l}$ represents the lift coefficient, and its value is 0 for spherical particles [31]; $\rho_{j}$ represents the density of the main phase; $\alpha_{i}$ represents the volume concentration of the secondary phase; $u_{j}$ represents the velocity of the main phase; $u_{i}$ represents the velocity of the secondary phase.

2.3. Solid Phase Control Model. The mixture movement and interaction of liquid and particles make the movement of particles complex and difficult to predict. Since this study is about the wear of high-volume concentration particles on the pump, the Lagrange method is used to describe the particle movement. The particle trajectory equation in the Lagrange method can be written as follows:

$$
\frac{\mathrm{d} u_{p}}{\mathrm{~d} t}=\frac{u-u_{p}}{\tau_{r}}+\frac{g\left(\rho_{p}-\rho\right)}{\rho_{p}}+F_{V}+F_{S}
$$

where $u_{p}=\mathrm{d} x / \mathrm{d} t, u$ represents fluid velocity, $u_{p}$ represents particle velocity, $\rho_{p}$ represents particle density, $\rho$ represents liquid density, $\left(u-u_{p}\right) / \tau_{r}$ represents the resistance per unit particle mass, and $\tau_{r}$ represents particle relaxation time and can be written as follows:

$$
\tau_{\mathrm{r}}=\frac{\rho_{\mathrm{p}} d_{\mathrm{p}}^{2}}{18 \mu} \frac{24}{\mathrm{C}_{\mathrm{d}} \operatorname{Re}_{\mathrm{p}}} .
$$

In the formula, $d_{p}$ represents particle diameter, $\mu$ represents fluid viscosity, $C_{d}$ represents the resistance coefficient, and $\mathrm{C}_{\mathrm{d}}$ can be expressed by the following formula:

$$
\mathrm{C}_{\mathrm{d}}=\alpha_{1}+\frac{\alpha_{2}}{\mathrm{Re}_{\mathrm{p}}}+\frac{\alpha_{3}}{\mathrm{Re}_{\mathrm{p}}^{2}} \text {. }
$$

In the above formula, $\alpha_{1}, \alpha_{2}$, and $\alpha_{3}$ are constants provided by Morsi and Alexander [33].

\subsection{Selection of Particle-Wall Rebound Function and Wear} Function. Many scholars [5, 16-25] put forward particlewall rebound functions and wear functions that are more suitable for their experiments according to different experimental conditions and explain the wear phenomenon under different conditions. According to its theoretical analysis, it is concluded that they are more suitable for wear under low-volume concentration conditions $(C<10 \%)$. For the high-volume concentration in this article, that is, the number of particles is too large, and to save the corresponding computing resources, the Fluent 18.0 built-in particle-wall rebound model and wear model are used. For specific models, refer to literature, which is adopted by Fluent 18.0 theory guide.

\section{Numerical Simulation Method}

3.1. Pump Model and Mesh Generation. The 1PN/4-3 KW single-stage centrifugal pump with open impeller is selected as the calculation and experimental model. The basic design parameters are shown in Table 1 . To reduce the influence of the liquid in and out of the centrifugal pump on the inside of the centrifugal pump, a $0.2 \mathrm{~m}$ pipe is added upstream of the impeller ( 4 times the diameter of the impeller inlet). A $0.12 \mathrm{~m}$ pipe is added at the outlet of the volute (4 times the diameter of the impeller outlet). NX12.0 software is used to build the corresponding model in Figure 1(a), and the computational grid uses ICEM to build a grid for the computational domain. The overall grid of the model is 4120245 , the number of nodes is 757118, and the corresponding calculation domain and grid are shown in Figure 1(b):

3.2. Model Verification. To verify the model, the numerical simulation and experimental results of the external characteristics of the model pump are compared. The results are shown in Figure 2. The curve error of the numerical simulation results and experimental results in the figure is less than $8 \%$. Considering the influence of factors such as valves and processing in the actual process, the external characteristic error of the model can be considered reasonable.

3.3. Calculation Model and Boundary Conditions. According to experience, the inlet of the centrifugal pump is set as a speed inlet, and the outlet is a pressure outlet. The velocities at the inlet and outlet of the continuous phase and the discrete phase are uniform, and the initial velocity of the discrete phase is equal to that of the continuous phase. In the calculation domain, the speed of the impeller remains constant, and the inlet pipe, outlet pipes, and volute remain stationary. The discrete phase and continuous phase adopt bidirectional coupling. DDPM model and turbulence model RNG $k-\varepsilon$ are used to calculate the wear of discrete phase on a centrifugal pump.

\section{Results and Discussion}

Numerical simulation is performed with the design conditions of the centrifugal pump with an open impeller (refer to Table 1) and the particle density of $2450 \mathrm{~kg} / \mathrm{m}^{3}$. The effects of flow rate and particle properties (particle size and volume concentration) on the wear characteristics of the centrifugal pump with open impeller are studied, respectively, and the wear law of the whole centrifugal pump is predicted, and the experimental results are compared (Table 2 is the numerical simulation working condition). The average wear rate and maximum wear rate of different parts of the centrifugal pump are calculated and compared. The pressure surface in this article is divided into the main working part of the blade, namely, the main pressure surface and the secondary pressure surface on the back blade. The suction surface is divided into the main working part of the blade, namely, the main suction surface and the secondary suction surface on the back blade. The graph shown in this article is a wear 
TABLE 1: Design parameters of the centrifugal pump.

\begin{tabular}{lccccc}
\hline Flow $\left(\mathrm{m}^{3} / \mathrm{h}\right)$ & Head $(\mathrm{m})$ & Rotating speed $(\mathrm{r} / \mathrm{min})$ & Inlet diameter $(\mathrm{mm})$ & Outlet diameter $(\mathrm{mm})$ & Number of blades \\
\hline 16 & 13 & 1450 & 50 & 25 & 5 \\
\hline
\end{tabular}

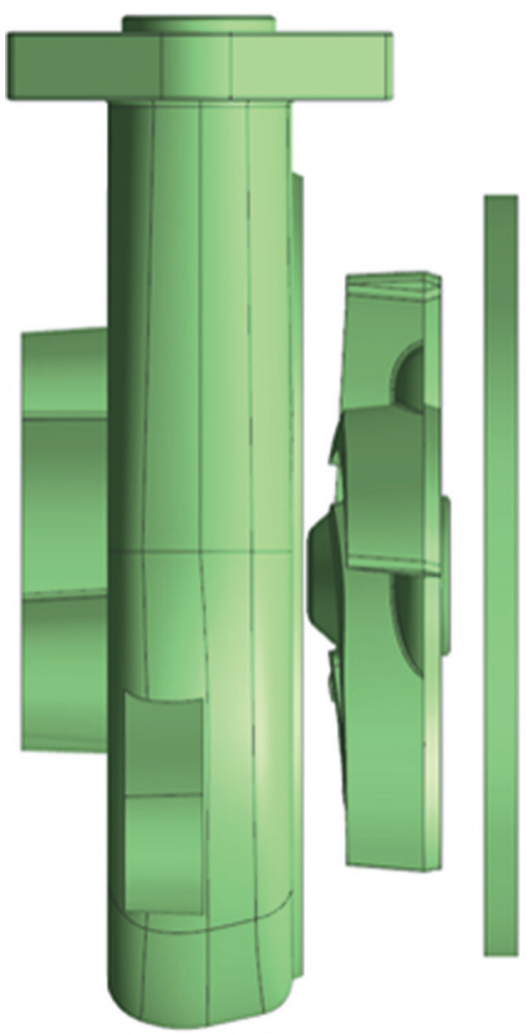

(a)

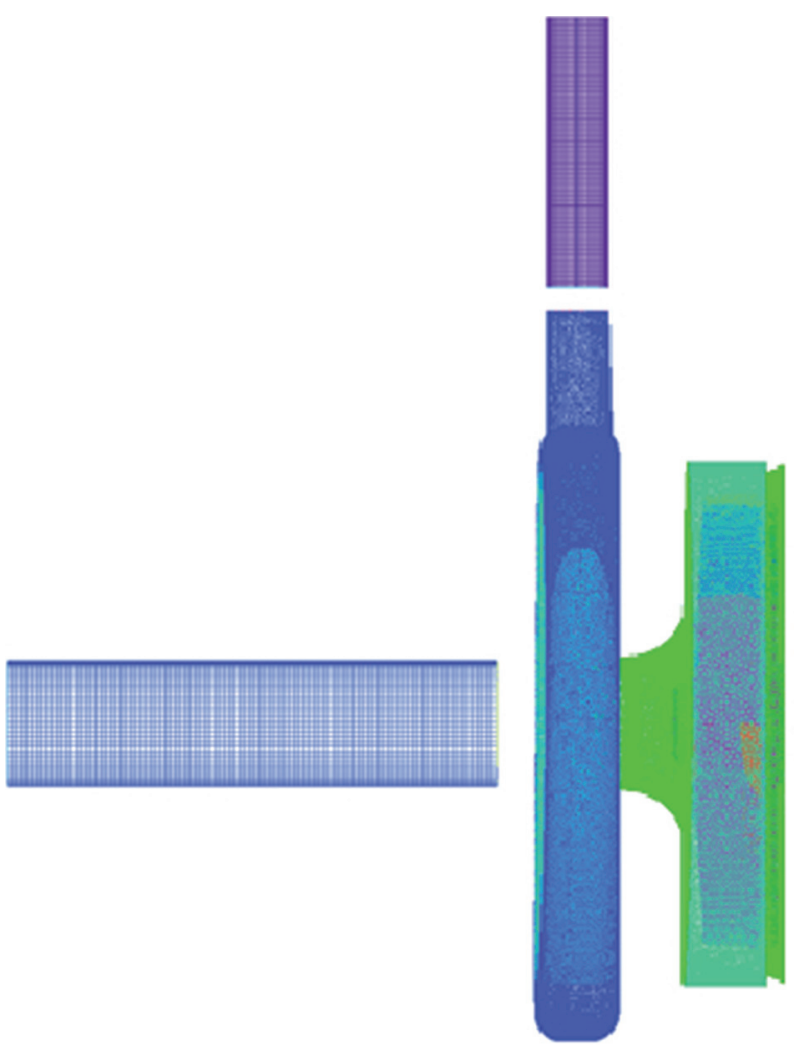

(b)

FIgURE 1: Centrifugal pump model and grid. (a) Centrifugal pump model; (b) centrifugal pump grid.

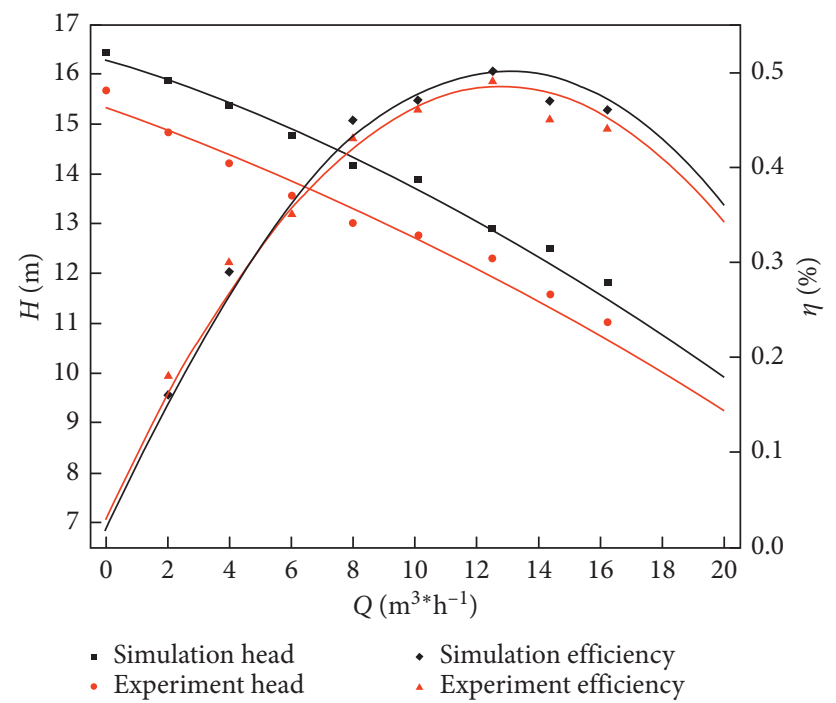

Figure 2: Verification of external characteristics of centrifugal pump. 
TABLE 2: Detailed operation conditions.

\begin{tabular}{lccr}
\hline Parameter & Cases $1-4$ & Cases 5-9 & Cases $10-14$ \\
\hline Flow rate $\left(\mathrm{m}^{3} \cdot \mathrm{h}^{-1}\right)$ & $9.6,12.8,16,19.2$ & 16 & 16 \\
Particle volume concentration $(\%)$ & 20 & 20 & $10,15,20,25,30$ \\
Particle diameter $(\mathrm{mm})$ & 0.106 & $0.048,0.106,0.15,0.27,0.425$ & 0.106 \\
\hline
\end{tabular}

cloud graph with time $t=0.5 \mathrm{~s}$, and the time when the wear rate (including the average wear rate and the maximum wear rate) is calculated is $t=0.2 \mathrm{~s}$.

\subsection{Influence of Flow Rate on Centrifugal Pump Wear.} Under the premise of volume concentration $C=20 \%$ and particle size $d=0.106 \mathrm{~mm}$, the influence of flow rate on the wear of the centrifugal pump with open impellers is studied. For cases 1-4 listed in Table 2, the flow rates include $Q=9.6 \mathrm{~m}^{3} \cdot \mathrm{h}^{-1}, 12.8 \mathrm{~m}^{3} \cdot \mathrm{h}^{-1}, 16 \mathrm{~m}^{3} \cdot \mathrm{h}^{-1}$, and $19.2 \mathrm{~m}^{3} \cdot \mathrm{h}^{-1}$, which correspond to the wear cloud diagram of different parts in Figures 3-6. The change of flow rate drives the change of particle velocity and effects of movement of high-volume concentration particle. Hence, the wear position of different parts of the centrifugal pump with an open impeller is changed.

Figure 3 shows that the increase of flow rate changes the wear position and wear amount of the whole impeller. Figures 4 and 5 reveal the wear cloud diagram of the pressure surface and suction surface of the blade. The increase of flow rate makes the wear of the pressure surface gradually increase and the wear location is concentrated in the middle of the pressure surface; moreover, the wear location of the suction surface moves from the foremost to the middle. Figure 6 indicates the effect of flow rate on the wear of the volute. The increase in flow rate makes the wear position of the volute change, but the main wear area is around the volute diaphragm. The change of flow rate makes the movement of the solid-liquid two-phase flow at the volute tongue change. The wear area near the volute tongue shows an expanding trend as a whole; the wear area of the volute tongue under design conditions is relatively small compared to others. Figure 7 shows the relationship between the wear rate and flow rate of different parts of the solid-liquid two-phase centrifugal pump. The main trend of the average rate of wall wear is increased. The maximum wear rate of the main suction surface decreases first and then increases with the increase of the flow rate, the maximum wear rate of volute increases, decreases, and then increases, and the others keep increasing.

The wear rate of the main parts of the centrifugal pump with open impeller (such as the main pressure surface, the main suction surface, and the volute) increases with the increase of the flow; the maximum wear rate of the main suction surface first increases and then decreases. The smallest value is under the design flow rate and the value of the maximum wear rate is the smallest, indicating that the maximum wear rate of the suction surface has a certain improvement under the design conditions.

4.2. The Influence of Particle Size on Centrifugal Pump Wear. Based on the design flow $Q=16 \mathrm{~m}^{3} \cdot \mathrm{h}^{-1}$ and the high-volume concentration $C=20 \%$, the effect of particle size on the wear of the centrifugal pump with an open impeller is studied. For cases 5-9 listed in Table 2, the particle sizes include $d=0.048 \mathrm{~mm}, 0.106 \mathrm{~mm}, 0.15 \mathrm{~mm}, 0.27 \mathrm{~mm}$, and $0.425 \mathrm{~mm}$, corresponding to the wear clouds in Figures 8-11. The change of particle size makes the particle more constrained by gravity and its own momentum changes. That is, the change of particle size makes the wear position of different parts of centrifugal pump with open impellers change.

The particle size has a great influence on the wear position of the impeller (see Figure 8). The larger the particle size, the more severe the wear of the front end of the impeller. Figures 9 and 10 show the influence of the particle size on the wear of the pressure surface and suction surface, respectively. The increase of particle size causes the wear position of the pressure surface to move from the front end to the middle, and the wear of the front end of the suction surface is worse. The wear position of the pressure surface moves downward with the increase of gravity (i.e., the increase in particle size). The main wear of the front end of the suction surface becomes more serious. Different from the impeller, the increase of the particle size first increases the wear range around the volute tongue and then decreases to a certain extent. The average wear rate of the volute and the secondary suction surface decreases with the increase of the particle size, and in the other position, the average wear rate increases (Figure 12(a)). The increase of the particle size reduces its followability, which reduces the collision probability of particles with the wall of the volute, so its average wear rate gradually decreases. The increase in particle size makes the maximum wear rate of the volute wall increase gradually. The maximum wear rate of the secondary suction surface decreases with the increase of the particle size, and the wear rate of the volute and suction surface is the largest among all parts (Figure 12(b)). It is because that the increase of particle size reduces the probability of particles colliding with the secondary suction surface. Hence, both the average wear rate and the maximum wear rate of the secondary suction surface decrease.

4.3. The Influence of Particle Volume Concentration on Centrifugal Pump Wear. Under the premise of design flow $Q=16 \mathrm{~m}^{3} \cdot \mathrm{h}^{-1}$ and particle size $d=0.106 \mathrm{~mm}$, the influence of volume concentration on the wear of the centrifugal pump with open impeller is studied. For cases 10-14 listed in Table 2, the volume concentration includes $C=10 \%, 15 \%$, $20 \%, 25 \%$, and $30 \%$ and the corresponding wear clouds are in Figures 13-16. The probability of particles hitting the centrifugal pump changes with the change of particle volume concentration, which has a great effect on the wear rate and wear location of the wall. 




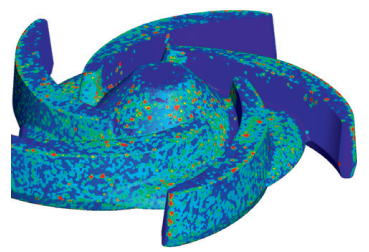

(a)



(b)



(c)

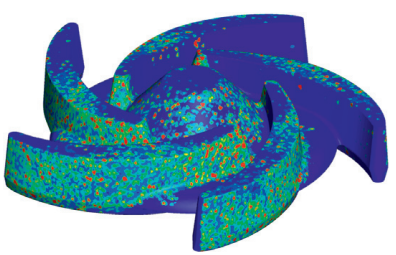

(d)

FIGURE 3: Impeller wear clouds at different flow rates. (a) $Q=9.6 \mathrm{~m}^{3} \cdot \mathrm{h}^{-1}$, (b) $Q=12.8 \mathrm{~m}^{3} \cdot \mathrm{h}^{-1}$, (c) $Q=16 \mathrm{~m}^{3} \cdot \mathrm{h}^{-1}$, and (d) $Q=19.2 \mathrm{~m}^{3} \cdot \mathrm{h}^{-1}$.

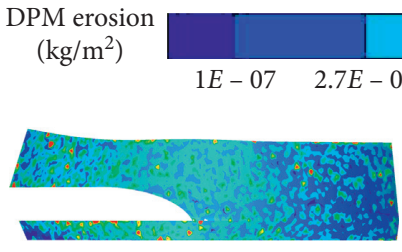

(a)

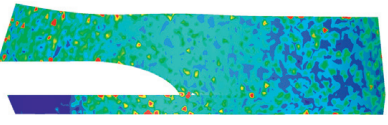

(b)

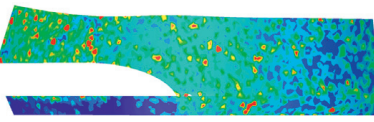

(c)

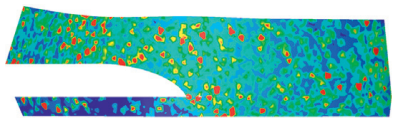

(d)

Figure 4: Pressure surface wear clouds at different flow rates. (a) $Q=9.6 \mathrm{~m}^{3} \cdot \mathrm{h}^{-1}$, (b) $Q=12.8 \mathrm{~m}^{3} \cdot \mathrm{h}^{-1}$, (c) $Q=16 \mathrm{~m}^{3} \cdot \mathrm{h}^{-1}$, and (d) $Q=19.2 \mathrm{~m}^{3} \cdot \mathrm{h}^{-1}$.

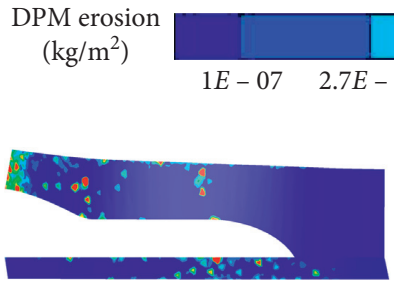

(a)

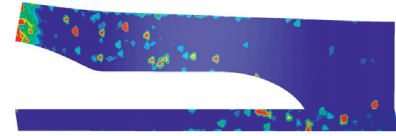

(b)

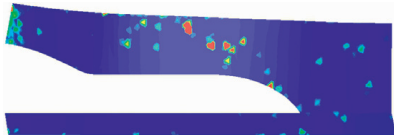

(c)

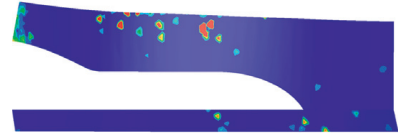

(d)

Figure 5: Suction surface wear clouds at different flow rates. (a) $Q=9.6 \mathrm{~m}^{3} \cdot \mathrm{h}^{-1}$, (b) $Q=12.8 \mathrm{~m}^{3} \cdot \mathrm{h}^{-1}$, (c) $Q=16 \mathrm{~m}^{3} \cdot \mathrm{h}^{-1}$, and (d) $Q=19.2 \mathrm{~m}^{3} \cdot \mathrm{h}^{-1}$.

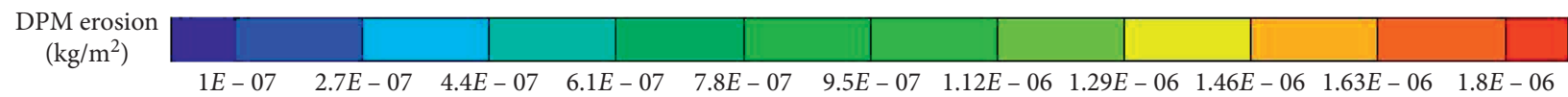

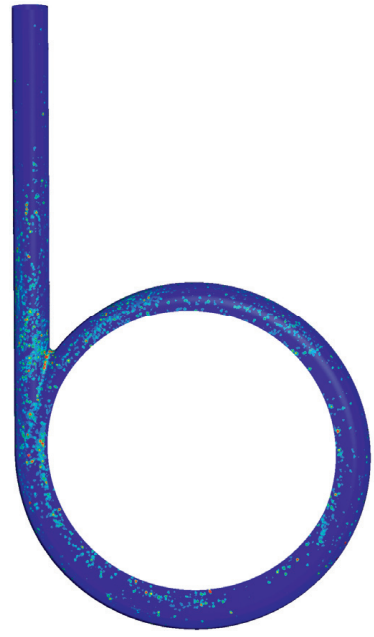

(a)

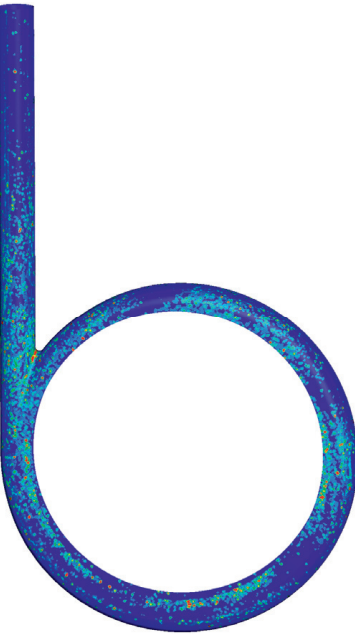

(b)

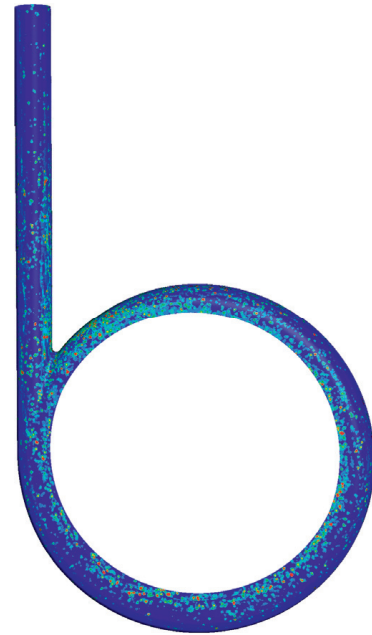

(c)

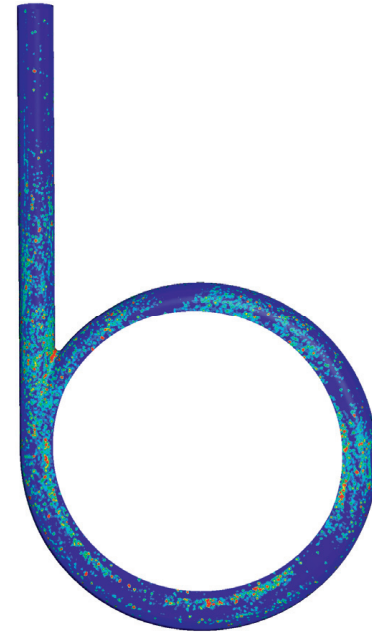

(d)

Figure 6: Volute wear clouds at different flow rates. (a) $Q=9.6 \mathrm{~m}^{3} \cdot \mathrm{h}^{-1}$, (b) $Q=12.8 \mathrm{~m}^{3} \cdot \mathrm{h}^{-1}$, (c) $Q=16 \mathrm{~m}^{3} \cdot \mathrm{h}^{-1}$, and (d) $Q=19.2 \mathrm{~m}^{3} \cdot \mathrm{h}^{-1}$. 


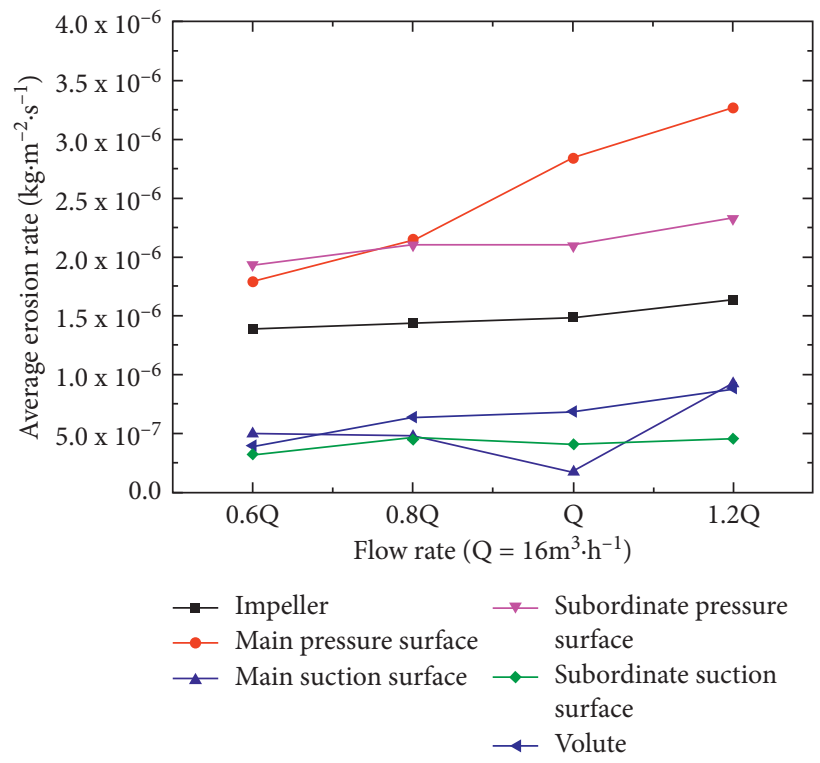

(a)

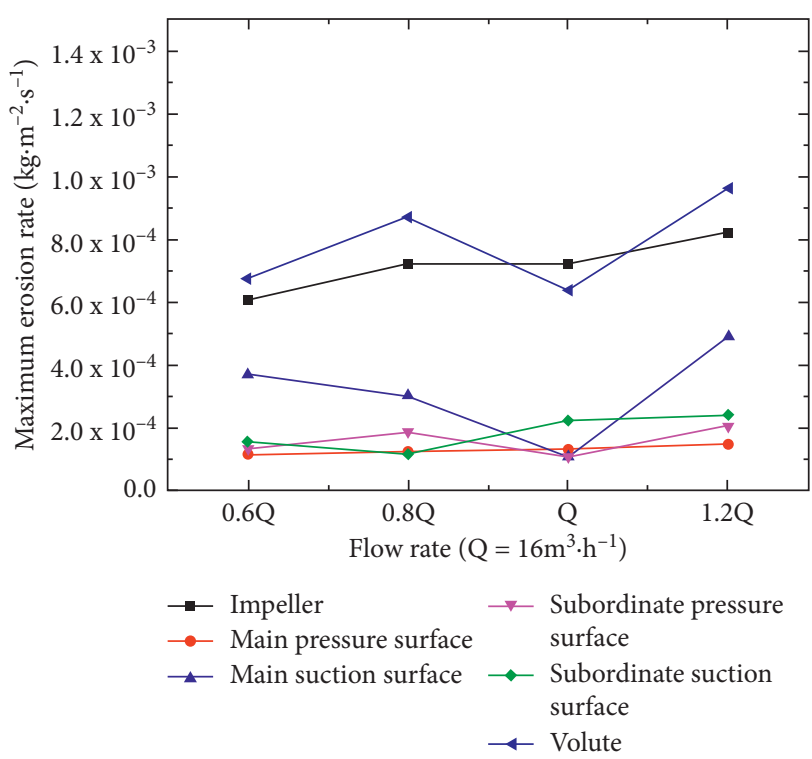

(b)

Figure 7: Comparison of wear rate of different parts at different flow rates. (a) Average wear rate; (b) maximum wear rate.

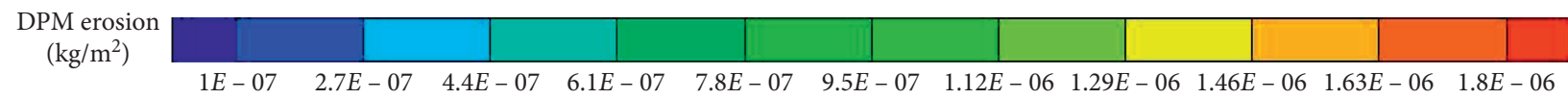

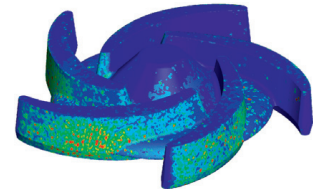

(a)



(b)



(c)

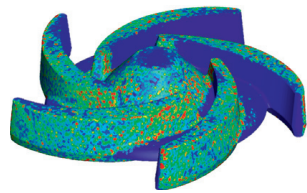

(d)

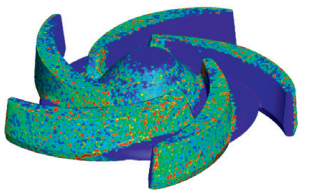

(e)

Figure 8: Impeller surface wear clouds at different particle sizes. (a) $d=0.048 \mathrm{~mm}$, (b) $d=0.106 \mathrm{~mm}$, (c) $d=0.15 \mathrm{~mm}$, (d) $d=0.27 \mathrm{~mm}$, and (e) $d=0.425 \mathrm{~mm}$.

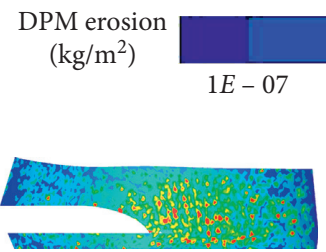

(a)

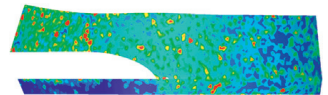

(b)

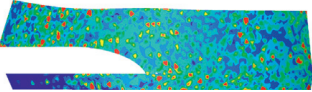

(c)

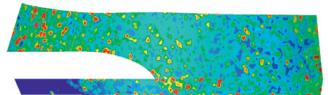

(d)

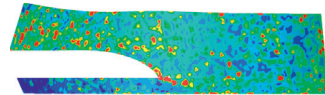

(e)

Figure 9: Pressure surface wear clouds at different particle sizes. (a) $d=0.048 \mathrm{~mm}$, (b) $d=0.106 \mathrm{~mm}$, (c) $d=0.15 \mathrm{~mm}$, (d) $d=0.27 \mathrm{~mm}$, and (e) $d=0.425 \mathrm{~mm}$.

With the increase in particle volume concentration, the wear of the impeller gradually increases (as shown in Figure 13). The area of the pressure surface wear spreads to the entire pressure surface and the amount of wear increases related to the particle size volume concentration increases (Figure 14). When the volume concentration is lower $(C<10 \%)$, the wear area of the suction surface is mainly concentrated in the front end, and when the volume concentration is higher $(C \geq 20 \%)$, it is mainly concentrated in the middle (Figure 15).

In Figure 16, with the increase in volume concentration, the main wear area of the volute extends from the tongue to the surrounding. The average wear rate of the secondary suction surface decreases and the other parts increases. The average wear rate of the main pressure surface shows an upward trend with the increase of the particle volume 


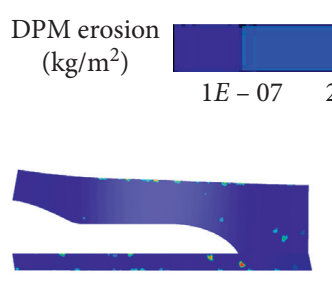

(a)

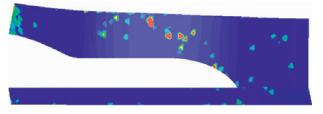

(b)



(c)



(d)

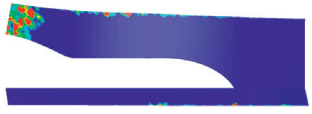

(e)

Figure 10: Suction surface wear clouds with different particle sizes. (a) $d=0.048 \mathrm{~mm}$, (b) $d=0.106 \mathrm{~mm}$, (c) $d=0.15 \mathrm{~mm},(\mathrm{~d}) d=0.27 \mathrm{~mm}$, and (e) $d=0.425 \mathrm{~mm}$.

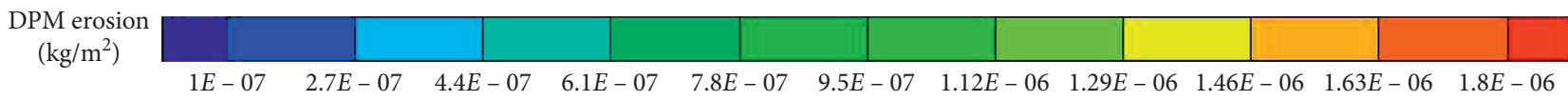

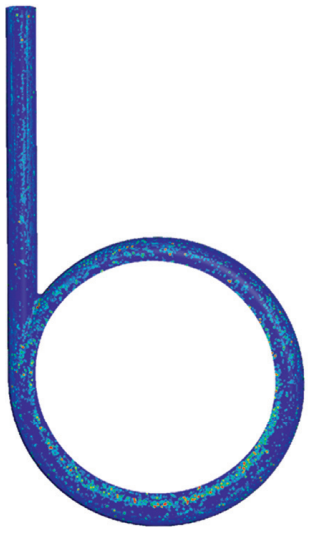

(a)

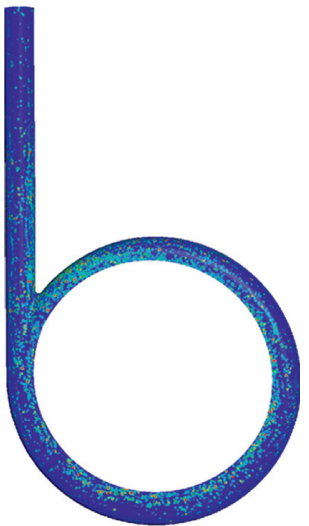

(b)

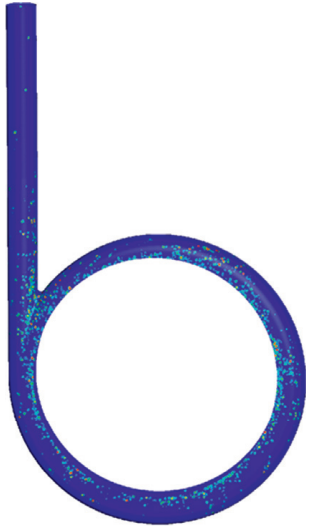

(c)

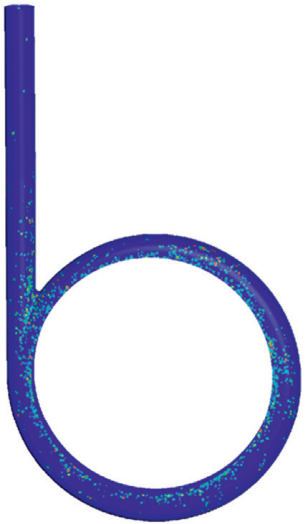

(d)

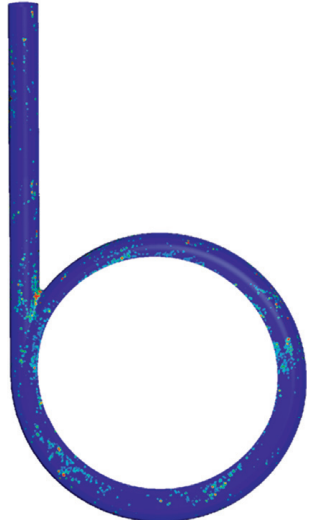

(e)

Figure 11: Volute wear clouds with different particle sizes. (a) $d=0.048 \mathrm{~mm}$, (b) $d=0.106 \mathrm{~mm}$, (c) $d=0.15 \mathrm{~mm},(\mathrm{~d}) d=0.27 \mathrm{~mm}$, and (e) $d=0.425 \mathrm{~mm}$.

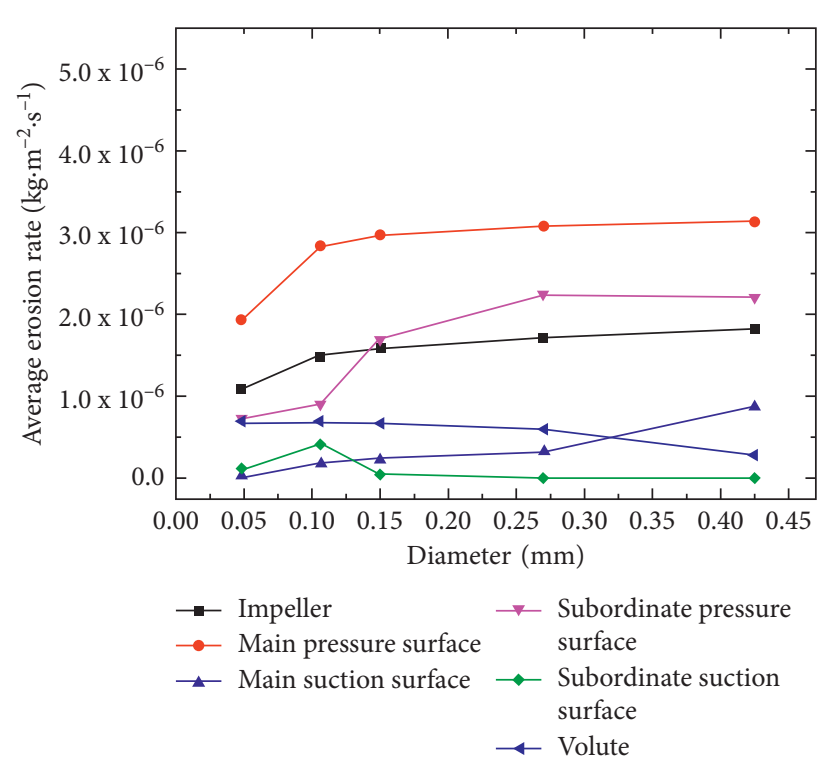

(a)

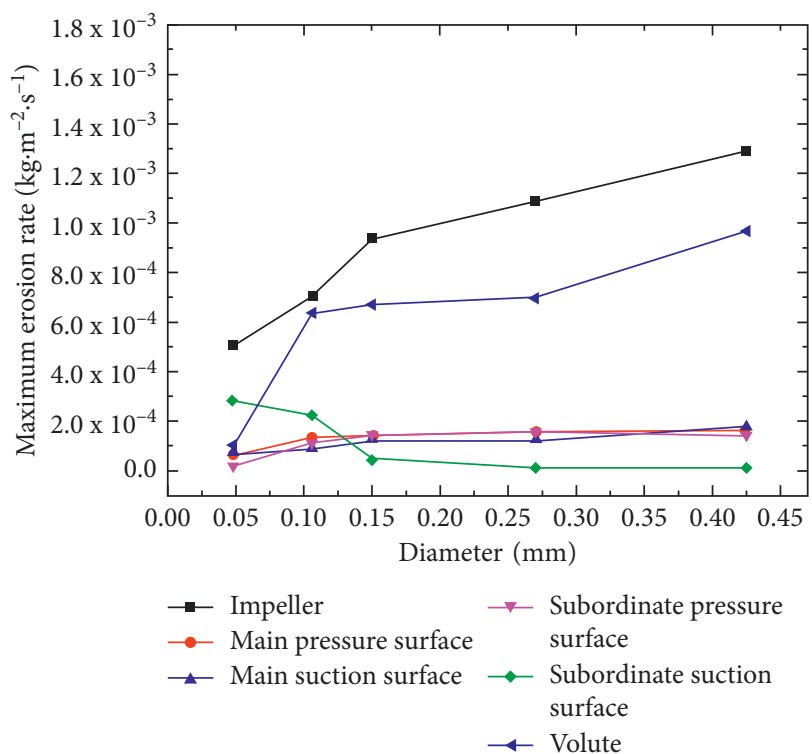

(b)

Figure 12: Comparison of wear rates of different parts at different particle sizes. (a) Average wear rate; (b) maximum wear rate. 


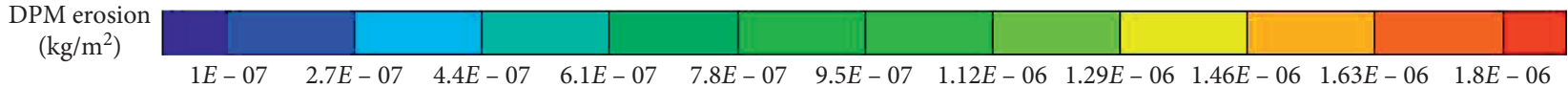

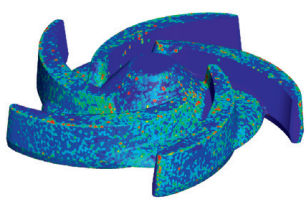

(a)

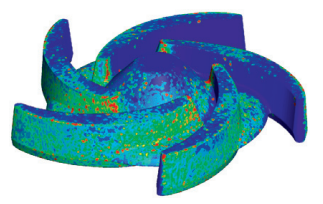

(b)



(c)

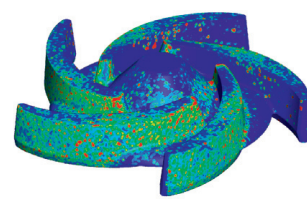

(d)

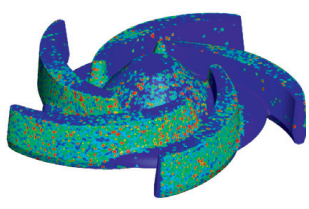

(e)

Figure 13: Impeller wear clouds at different particle volume concentrations. (a) $C=10 \%$, (b) $C=15 \%$, (c) $C=20 \%,(d) C=25 \%$, and (e) $C=30 \%$.

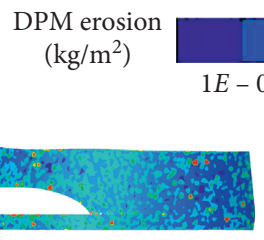

(a)

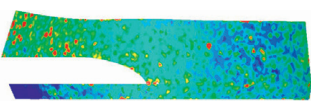

(b)

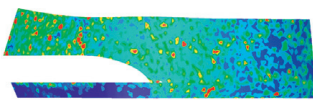

(c)



(d)

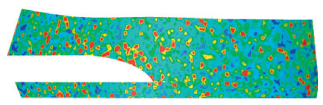

(e)

Figure 14: Pressure surface wear clouds at different particle volume concentrations. (a) $C=10 \%$, (b) $C=15 \%,(\mathrm{c}) C=20 \%$, (d) $C=25 \%$, and (e) $C=30 \%$.

DPM erosion

$\left(\mathrm{kg} / \mathrm{m}^{2}\right)$

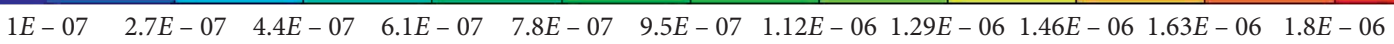



(a)



(b)

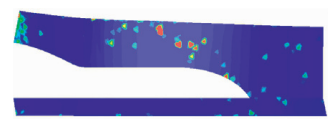

(c)

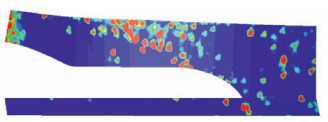

(d)

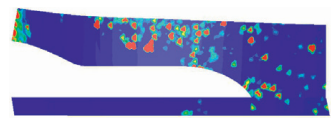

(e)

Figure 15: Suction surface wear clouds at different particle volume concentrations. (a) $C=10 \%$, (b) $C=15 \%,(\mathrm{c}) C=20 \%,(d) C=25 \%$, and (e) $C=30 \%$.

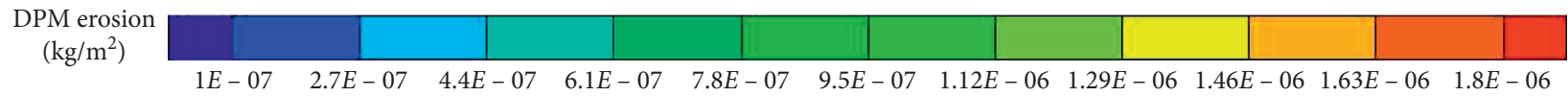

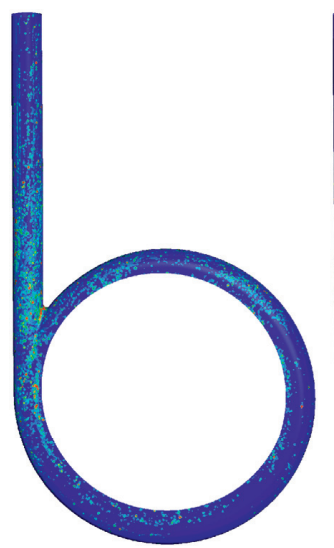

(a)

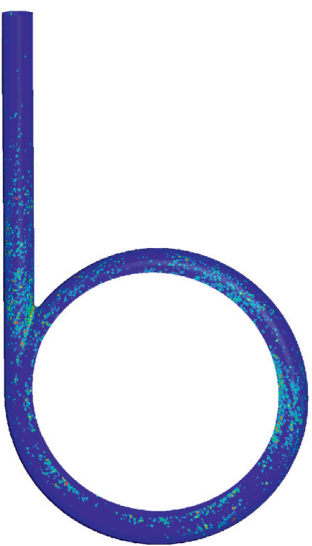

(b)

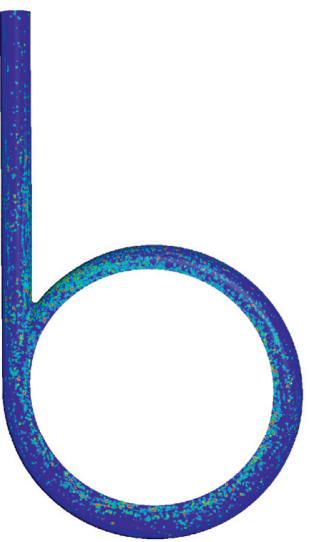

(c)

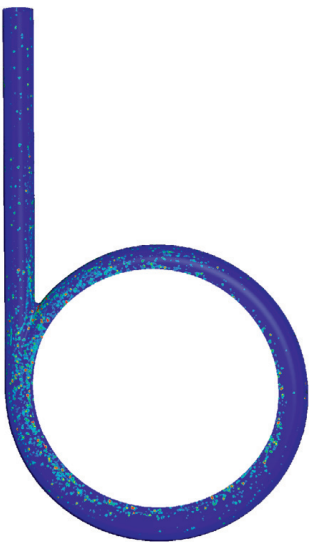

(d)

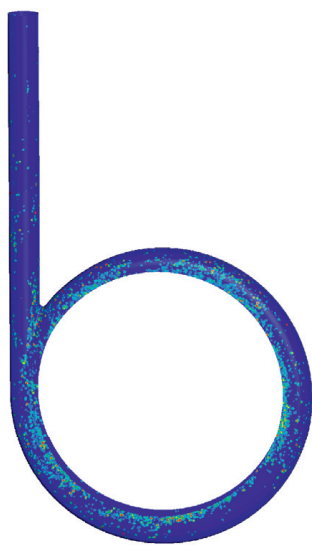

(e)

Figure 16: Volute wear clouds at different particle volume concentrations. (a) $C=10 \%$, (b) $C=15 \%$, (c) $C=20 \%$, (d) $C=25 \%$, and (e) $C=30 \%$. 


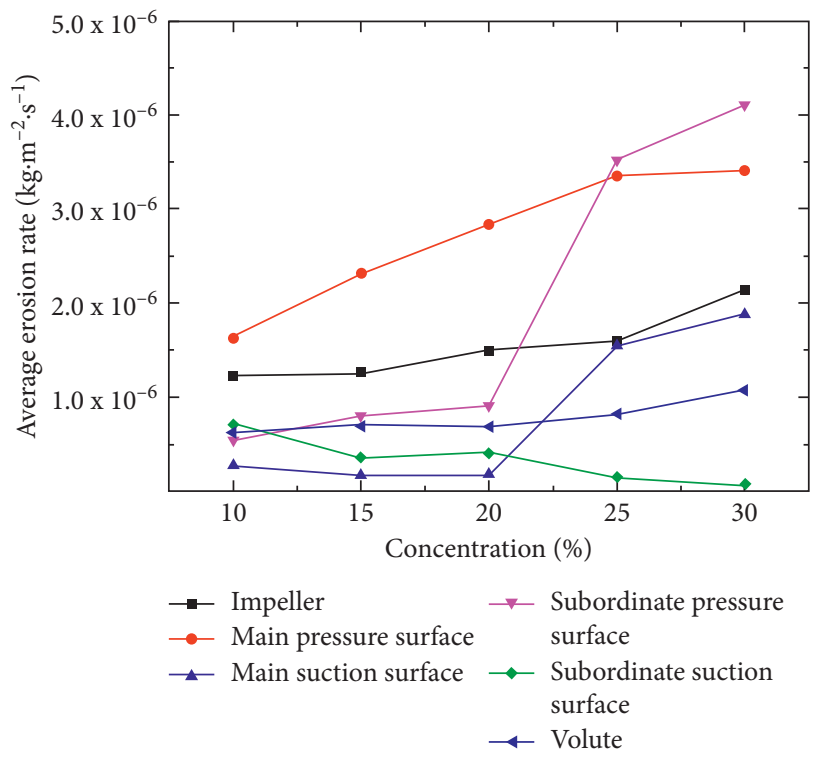

(a)

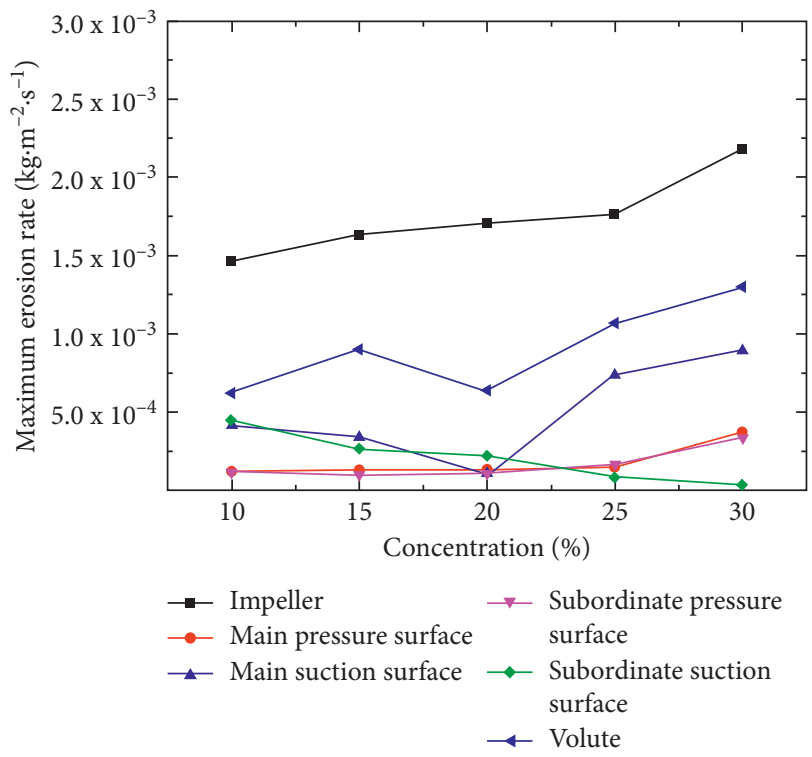

(b)

Figure 17: Comparison of wear rates of different parts at different particle volume concentrations. (a) Average wear rate; (b) maximum wear rate.

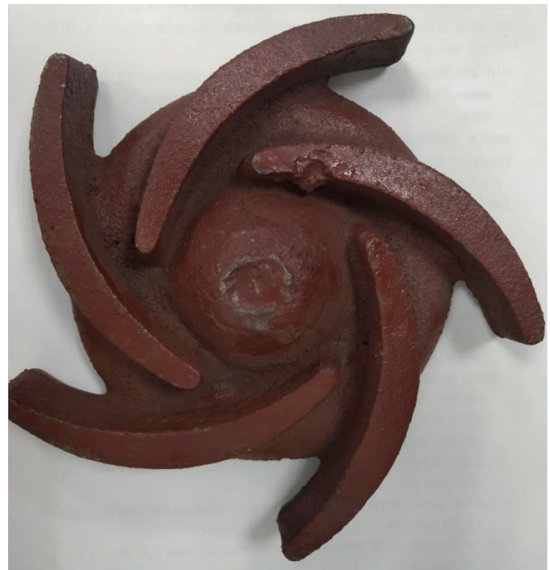

(a)

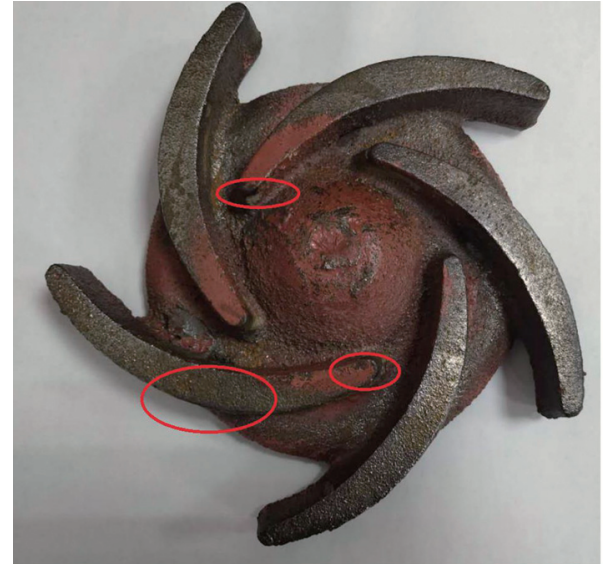

(b)

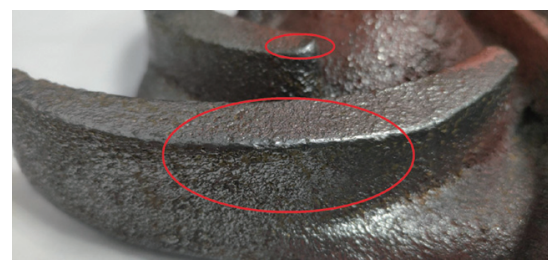

(c)

FIGURE 18: Wear numerical simulation and experimental comparison of the impeller. (a) Impeller before experiment; (b) experimental wear of impeller; (c) experimental wear of pressure surface.

concentration and maintains the maximum average rate of all parts. The average wear rate of the secondary suction surface is varying from $20 \%$ to $25 \%$ in all parts, which is the largest in Figure 17(a). The increase of particle volume concentration causes the maximum wear rate of the main suction surface to first decrease and then increase, the secondary suction surface maintains a consistent downward trend, and the other parts maintain an upward trend (Figure 17(b)).

The increase of volume concentration makes the main wear area of the pressure surface extend from the front end 
to the tail. The average wear rate and maximum wear rate of the main pressure surface increase and the average wear rate of the secondary pressure surface increases, but the maximum wear rate of the secondary pressure surface decreases first and then increases with the increase of volume concentration. The average wear rate and maximum wear rate of the main suction surface increase. The particles with highvolume concentration will aggregate; as the volume concentration increases, more particles are located in the flow channel of the impeller, which makes the average wear and maximum wear of the secondary suction surface show a downward trend. The degree of wear around the volute tongue increases with the increase of particle volume concentration, the average wear rate gradually increases, and the maximum wear rate first decreases and then increases.

4.4. Centrifugal Pump Wear Test Comparison. Figure 18(a) is the painted impeller before the impeller wear test. Figures 18(b), and 18(c) are the wear test results of a centrifugal pump with the open impeller at the condition of volume concentration $C=20 \%$, particle diameter $d=0.106 \mathrm{~mm}$, and flow rate $Q=16 \mathrm{~m}^{3} \cdot \mathrm{h}^{-1}$ and centrifugal pump running 48 hours. It can be seen intuitively that the main wear positions of the impeller appear in the middle of the blade and the front end of the blade. By comparing the wear map of the impeller experiment (Figures 18(b), and 18(c)) with the wear cloud map in the simulation (Figures 3(c) and 4(c)), it is found that the wear position of the impeller appears at the middle and the leading edge of the blade, which is almost similar to that of the numerical simulation. When using this type of centrifugal pump to convey high-volume concentration particles, the wear resistance of the middle part of the impeller blade and the leading edge of the blade should be considered.

\section{Conclusion}

The wear of the centrifugal pumps with open impellers that convey high-volume concentrations of particles is mainly caused by particle movement. In this study, the three-dimensional unsteady and two-phase coupling Euler-Lagrange method is used to simulate the wear of the centrifugal pump with an open impeller. Through the analysis of the wear cloud diagram, it is concluded that when the centrifugal pump delivers high-volume concentration solid-liquid twophase flow, the main wear part appears on the pressure surface of the impeller. Compared with other parts, the average wear rate of the main pressure surface is the largest. The second is the part of the volute tongue. According to the numerical simulation of the change of the wear cloud image of the volute tongue, it is concluded that the two-phase flow is extremely active around it, and the probability of particles colliding with the surrounding wall is greatly increased, which increases the wear rate. Parameters such as flow rate, particle size, and particle volume concentration mainly have a significant impact on the wear of the leading edge, the middle of the blade, and the volute tongue of the centrifugal pump with an open impeller.

\section{Data Availability}

All data included in this study are available upon request by contact with the corresponding author.

\section{Conflicts of Interest}

The authors declare no conflicts of interest.

\section{Acknowledgments}

The authors acknowledge the financial support of National Natural Science of China and the Key Research and Development Program of Zhejiang Province. The work was supported by NSFC (Grant no. 51676174) and Key Research and Development Program of Zhejiang Province (Grant no. 2020C1027).

\section{References}

[1] T. Lin, Z. Zhu, X. Li, J. Li, and Y. Lin, "Theoretical, experimental, and numerical methods to predict the best efficiency point of centrifugal pump as turbine," Renewable Energy, vol. 168, no. 5, pp. 31-44, 2021.

[2] Y. Yang, L. Zhou, W. Shi, Z. He, Y. Han, and Y. Xiao, "Interstage difference of pressure pulsation in a three-stage electrical submersible pump," Journal of Petroleum Science and Engineering, vol. 196, Article ID 107653, 2021.

[3] X. Li, T. Shen, P. Li, X. Guo, and Z. Zhu, "Extended compressible thermal cavitation model for the numerical simulation of cryogenic cavitating flow," International Journal of Hydrogen Energy, vol. 45, no. 16, pp. 10104-10118, 2020.

[4] L. Zhou, C. Han, L. Bai, W. Li, M. A. El-Emam, and W. Shi, "CFD-DEM bidirectional coupling simulation and experimental investigation of particle ejections and energy conversion in a spouted bed," Energy, vol. 211, no. 15, p. 118672, 2020.

[5] Y. Zhang, E. P. Reuterfors, B. S. McLaury, S. A. Shirazi, and E. F. Rybicki, "Comparison of computed and measured particle velocities and erosion in water and air flows," Wear, vol. 263, no. 1-6, pp. 330-338, 2007.

[6] C. Sunil, S. N. Singh, and V. Seshadri, "A comparative study on the performance characteristics of centrifugal and progressive cavity slurry pumps with high volume concentration fly ash slurries," Particulate Science and Technology, vol. 29, no. 4, pp. 378-396, 2011.

[7] B. Wu, X.-L. Wang, H. Liu, and H.-L. Xu, "Numerical simulation and analysis of solid-liquid two-phase three-dimensional unsteady flow in centrifugal slurry pump," Journal of Central South University, vol. 22, no. 8, pp. 3008-3016, 2015.

[8] B. K. Gandhi, S. N. Singh, and V. Seshadri, "Performance characteristics of centrifugal slurry pumps," Journal of Fluids Engineering, vol. 123, no. 2, pp. 271-280, 2001.

[9] T. Engin and M. Gur, "Comparative evaluation of some existing correlations to predict head degradation of centrifugal slurry pumps," Journal of Fluids Engineering, vol. 125, no. 1, pp. 149-157, 2003.

[10] M. C. Roco, P. Nair, and G. R. Addie, "Casing headloss in centrifugal slurry pumps," Journal of Fluids Engineering, vol. 108, no. 4, pp. 453-464, 1986.

[11] K. C. Wilson, G. R. Addie, A. Sellgren, and R. Clift, Pump Selection and Cost Considerations, Springer, Boston, MA, USA, 2006. 
[12] B. K. Gandhi and S. V. Borse, "Effects of particle size and size distribution on estimating erosion wear of cast iron in sandwater slurries," Indian Journal of Engineering \& Materials Sciences, vol. 9, no. 6, pp. 480-486, 2002.

[13] Y. Ben-Ami, A. Uzi, and A. Levy, "Modelling the particles impingement angle to produce maximum erosion," Powder Technology, vol. 301, pp. 1032-1043, 2016.

[14] L. Nan, H. Arabnejad, S. A. Shirazi et al., "Experimental study of particle size, shape and particle flow rate on Erosion of stainless steel," Powder Technology, vol. 336, pp. 70-79, 2018.

[15] F. Lai, Y. Wang, S. A. EI-Shahat, G. Li, and X. Zhu, "Numerical study of solid particle erosion in a centrifugal pump for liquid-solid flow," Journal of Fluids Engineering, vol. 141, no. 12, Article ID 121302, 2019.

[16] Y. Zhang, Y. Li, B. Cui, Z. Zhu, and H. Dou, "Numerical simulation and analysis of solid-liquid two-phase flow in centrifugal pump," Chinese Journal of Mechanical Engineering, vol. 26, no. 1, pp. 53-60, 2013.

[17] W. P. Adamczyk, A. Klimanek, R. A. Białecki, G. Węcel, P. Kozołub, and T. Czakiert, "Comparison of the standard Euler-Euler and hybrid Euler-Lagrange approaches for modeling particle transport in a pilot-scale circulating fluidized bed," Particuology, vol. 15, no. 4, pp. 129-137, 2014.

[18] G. Ou, K. Bie, Z. Zheng, G. Shu, C. Wang, and B. Cheng, "Numerical simulation on the erosion wear of a multiphase flow pipeline," The International Journal of Advanced Manufacturing Technology, vol. 96, no. 5-8, pp. 1705-1713, 2018.

[19] V. Jain, L. Kalo, D. Kumar, H. J. Pant, and R. K. Upadhyay, "Experimental and numerical investigation of liquid-solid binary fluidized beds: radioactive particle tracking technique and dense discrete phase model simulations," Particuology, vol. 33, no. 4, pp. 112-122, 2017.

[20] M. Sommerfeld and N. Huber, "Experimental analysis and modelling of particle-wall collisions," International Journal of Multiphase Flow, vol. 25, no. 6-7, pp. 1457-1489, 1999.

[21] A. Forder, M. Thew, D. Harrison et al., "A numerical investigation of solid particle erosion experienced within oilfield control valves," Wear, vol. 216, no. 2, pp. 184-193, 1998.

[22] J. G. A. Bitter, "A study of erosion phenomena part I," Wear, vol. 6, no. 1, pp. 5-21, 1963.

[23] J. G. A. Bitter, "A study of erosion phenomena," Wear, vol. 6, no. 3, pp. 169-190, 1963.

[24] J. H. Neilson and A. Gilchrist, "Erosion by a stream of solid particles," Wear, vol. 11, no. 2, pp. 111-122, 1968.

[25] Y. I. Oka, K. Okamura, T. Yoshida et al., "Practical estimation of erosion damage caused by solid particle impact," Wear, vol. 259, no. 1-6, pp. 95-101, 2005.

[26] Y. I. Oka and T. Yoshida, "Practical estimation of erosion damage caused by solid particle impact," Wear, vol. 259, no. 1-6, pp. 102-109, 2005.

[27] C. Huang, S. Chiovelli, P. Minev, J. Luo, and K. Nandakumar, "A comprehensive phenomenological model for erosion of materials in jet flow," Powder Technology, vol. 187, no. 3, pp. 273-279, 2008.

[28] I. Finnie, "Erosion of surfaces by solid particles," Wear, vol. 3, no. 2, pp. 87-103, 1960.

[29] G. Grant and W. Tabakoff, "Erosion prediction in turbomachinery resulting from environmental solid particles," Journal of Aircraft, vol. 12, no. 5, pp. 471-478, 1975.

[30] A. V. Levy and W. Buqian, "Erosion of hard material coating systems,” Wear, vol. 121, no. 3, pp. 325-346, 1988.
[31] J. S. Marshall, "Discrete-element modeling of particulate aerosol flows," Journal of Computational Physics, vol. 228, no. 5, pp. 1541-1561, 2009.

[32] R. Mei, "An approximate expression for the shear lift force on a spherical particle at finite Reynolds number," International Journal of Multiphase Flow, vol. 18, no. 1, pp. 145-147, 1992.

[33] S. A. Morsi and A. J. Alexander, "An investigation of particle trajectories in two-phase flow systems," Journal of Fluid Mechanics, vol. 55, no. 2, pp. 193-208, 1972. 